\title{
Cameras and settings for aerial surveys in the geosciences:
}

\section{optimizing image data}

\author{
James O’Connor ${ }^{1+}$, Mike Smith ${ }^{1}$, Mike R. James ${ }^{2}$ \\ ${ }^{1}$ School of Geography and Geology, Kingston University London \\ ${ }^{2}$ Lancaster Environment Centre, Lancaster University
}

Keywords: UAV, Digital Image, Photography, Remote Sensing

\begin{abstract}
:
Aerial image capture has become very common within the geosciences due to the increasing affordability of low payload ( $<20 \mathrm{~kg}$ ) Unmanned Aerial Vehicles (UAVs) for consumer markets. Their application to surveying has subsequently led to many studies being undertaken using UAV imagery and derived products as primary data sources. However, image quality and the principles of image capture are seldom given rigorous discussion. In this contribution we firstly revisit the underpinning concepts behind image capture, from which the requirements for acquiring sharp, well exposed and suitable image data are derived. Secondly, the platform, camera, lens and imaging settings relevant to image quality planning are discussed, with worked examples to guide users through the process of considering the factors required for capturing high quality imagery for geoscience investigations.

Given a target feature size and ground sample distance based on mission objectives, flight height and velocity should be calculated to ensure motion blur is kept to a minimum. We recommend using a camera with as big a sensor as is permissible for the aerial platform being used (to maximise sensor sensitivity), effective focal lengths of $24-35 \mathrm{~mm}$ (to minimize errors due to lens distortion) and optimising ISO (to ensure shutter speed is fast enough to minimise motion blur). Finally, we give recommendations for the reporting of results by researchers in order to help improve the confidence in, and reusability of, surveys through: providing open access imagery where possible, presenting example images and excerpts, and detailing appropriate metadata to rigorously describe the image capture process.
\end{abstract}


${ }^{\dagger}$ Corresponding author:

James O'Connor, School of Natural and Built Environments, Kingston University, Penrhyn Road, Kingston upon Thames, Surrey, KT21EE, UK

Email: james.oconnor@kingston.ac.uk

Contact number: 07857247850

Contact address: Doctoral school, Kingston University, KT12EE, Penrhyn road 


\section{Introduction}

The earliest use of digital images for geoscience surveys relied on photographic prints made from conventional negative film, which were then digitally scanned for processing (Butler et al., 1998; Chandler and Padfield, 1996; Lane et al., 2000; Pyle et al., 1997). However, this workflow began to phase out with the advent of consumer level digital cameras, which were adopted from the late 1990s for applications such as making maps of settlements (Mason et al., 1997), measurement of river-channel change (Chandler et al., 2002), producing digital elevation models (DEMs) for generating bed roughness parameters (Chandler et al., 2000) and remote sensing of vegetation (Dean et al., 2000). The earliest cameras, such as the Kodak DCS460, had sensors with low pixel counts ( 6 megapixels) and were relatively large and heavy $(1.7 \mathrm{~kg})$, but some pioneering studies were performed from unmanned aerial platforms using kites (Aber et al., 2002; Ught, 2001). Substantial efforts were made to explore how well such consumer cameras could be calibrated for use in photogrammetric contexts, and hence be used as a substitute for expensive conventional aerial surveys with metric cameras (Ahmad and Chandler, 1999; Shortis et al., 1998). Since the 1990s, the application of digital cameras in the geosciences has accelerated rapidly due to significant improvements in camera design and miniaturisation and their relatively low cost $(<\$ 1,000)$.

In parallel to developments in consumer-grade cameras, there have been recent and rapid advances in the use of unmanned aerial vehicles (UAVs), defined here as "uninhabited and reusable motorised vehicles, which are remotely controlled, semi-autonomous, autonomous, or have a combination of these capabilities, and can carry various types of payloads" (van Blyenburgh, 1999), for low altitude aerial photography. In particular, these have allowed geoscientific investigation to be undertaken at low cost, collecting high temporal and spatial resolution image data from which orthomosaics and DEMs can be derived (Anderson and Gaston, 2013; Smith et al., 2009). Recent examples demonstrate a host of application areas such as the analysis of watersheds (Ouedraogo et al., 2014; Rippin et al., 2015), crop monitoring (Geipel et al., 2014; Hunt et al., 2010; Rokhmana, 2015), structural geology (Bemis et al., 2014; Rock et al., 2011; Vasuki et al., 2014), glacial mapping 
(Immerzeel et al., 2014; Ryan et al., 2015; Whitehead et al., 2013), monitoring erosion processes (d'Oleire-Oltmanns et al., 2012; Eltner et al., 2013; Marzolff and Poesen, 2009; Smith and Vericat, 2015), landslides (Lucieer et al., 2014b; Niethammer et al., 2010; Turner et al., 2015) and forestry (Fritz et al., 2013; Lisein et al., 2013; Puliti et al., 2015).

Many of these aerial images are being used to produce topographic data using modern structurefrom-motion (SfM) algorithms (Bemis et al., 2014; Smith et al., 2015). The ability of SfM approaches to carry out automatic camera calibration and image orientation has largely removed photogrammetric expertise as a pre-requisite for achieving straightforward models (Remondino and Fraser, 2006) but has consequently also raised issues over data quality. However, providing sufficient image metadata when reporting is important to help provide confidence in results and to facilitate reproducibility. In addition, there is scope for reported accuracies within studies to be discussed in terms of the characteristics and quality of the acquired image data, which are the raw data that underpin all the subsequent analyses.

Although there has been substantial consideration of UAV performance and image processing approaches (Eisenbeiss, 2006; Lucieer et al., 2014a; Verhoeven et al., 2015), camera specifications and the parameters selected for image capture have been less widely discussed. Sharpness and exposure have a direct impact on the usefulness of collected data, and camera settings, optimal or not, are underreported within the literature (Lucieer et al., 2014a). Ground sample distance (GSD), the distance on the ground covered by each pixel (assuming the camera is stationary and observing orthogonal to the surface), is often the sole reported metric (d'Oleire-Oltmanns et al., 2012).

Thus, in this paper, we focus on camera characteristics and settings for UAV-based image capture, which form a vital part of UAV survey planning. A consideration of the full survey planning process (i.e. flight paths, distribution of ground control) is outside of the remit of our work but the underpinning considerations are detailed within the conventional aerial survey literature (Kraus, 2007; McGlone, 2013). Here we review the underlying principles of digital image capture and 
consider how they influence the required camera characteristics and acquisition settings to ensure sharp, well exposed imagery. We review typical camera settings used in geoscientific UAV surveys, specifically targeting small UAV systems (mass of less than $20 \mathrm{~kg}$ (Civil Aviation Authority, 2010)) and make recommendations for their optimisation. We present a worked planning example, and illustrate the principles in two real-world case studies, where we discuss planning and limitations of survey design with regards to image quality. 


\section{Principles of digital image capture}

To capture a digital image the light reflected or emitted from a scene is collected by a camera and converted into electrical signals that are measured and stored. The area captured, or field of view (FOV; Figure 1a), is a function of the focal length, $f$, of the camera lens, and the size of the sensor (e.g. sensor width/height, w) onto which the image is projected (Clodius, 2007)

$$
F o V=2 \arctan \left(\frac{w}{2 f}\right) \approx \frac{w}{f}
$$

where focal length is the distance between the centre of the lens and the point of convergence of parallel light rays incident on the lens when it is focused at infinity (Hecht, 2011). The point of convergence of these light rays is where the sharpest image is formed (Figure 1b) and, for a wellfocussed, sharp image, this coincides with the location of the sensor.
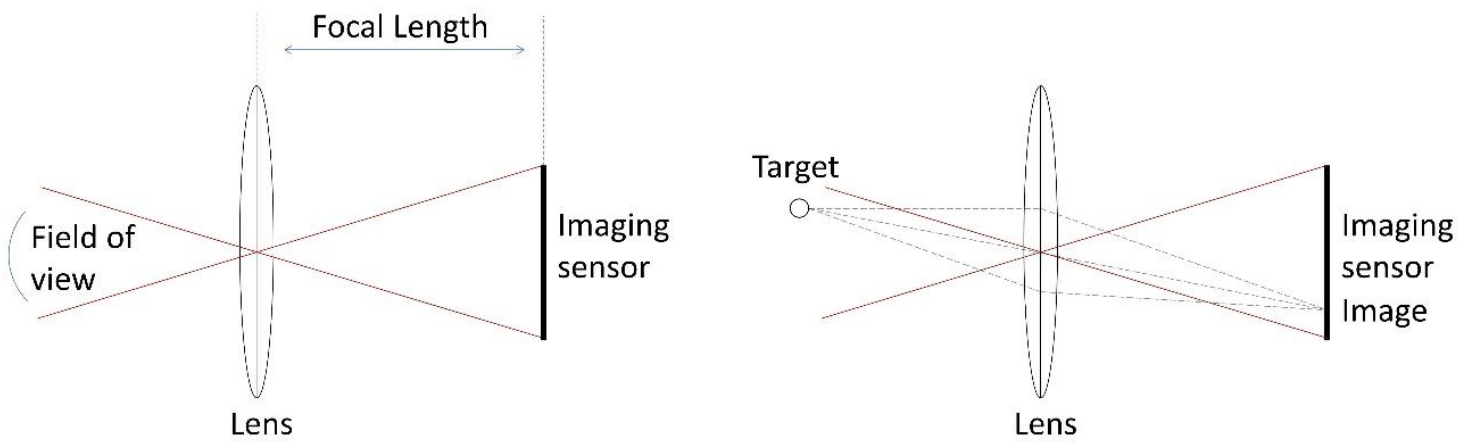

Figure 1. (a) Field of view of a camera system and (b) example light rays incident on the sensor.

The 'sensor' is the photosensitive element in the camera that converts light into an electrical response and comprises an active semiconductor overlaying a substrate of 'photosites' (Gupta, 2013). On exposure, light incident on the semiconductor layer causes an electrical charge to be transferred to the photosites, where it is then measured, site by site, to recover a full image. To distinguish colour most consumer cameras use a colour filter array (CFA) over the sensor, which restricts the wavelengths of light recorded by each photosite (Figure 2), making them sensitive to 
red, blue or green. In order to reconstruct the full colour image, cameras then interpolate the information from same-colour photosites over the entire sensor, in a process known as demosaicing. The outputs from this process are three different colour 'bands' which represent the red, green and blue portions of a colour image. Consumer cameras typically use CFAs with colours arranged in a 'Bayer' pattern (Figure 2a), in which there are twice the number of green filters (as the human eye is more sensitive to green) than red or blue.

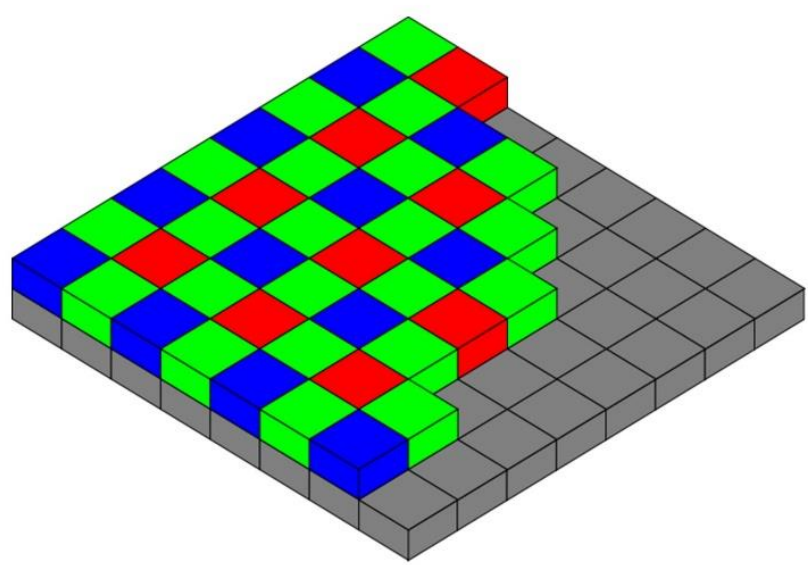

(a)

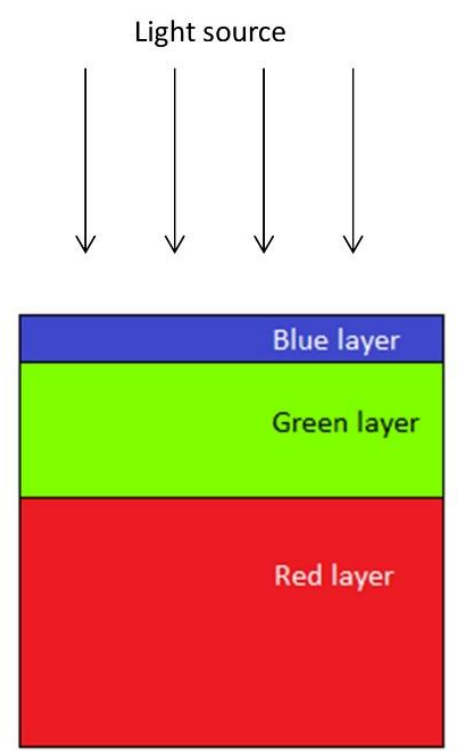

(b)

Figure 2. Colour discrimination in consumer cameras is performed by using either a colour filter array, such as the Bayer array (a) or, less commonly, by different layers in a 'direct imaging sensor' (b) in which light at different wavelengths (colour) penetrate to different depths.

Some cameras (e.g. Sigma DP2) do not use a CFA to distinguish colour, but rather a sensor comprising three layers of photosensitive elements (Figure $2 \mathrm{~b}$ ). As the penetrative capability of light is a function of wavelength, the varying depths of the layers within the sensor make them sensitive to different colours. These 'direct image sensors' are typically more expensive to produce than equivalent resolution CFA-based sensors, but their outputs don't require demosaicing and have been shown to capture sharp edges at higher quality (Hubel et al., 2004). However, such sensors are not 
commonly used, and thus have yet to be tested thoroughly over a wide range of geoscience imaging applications.

As output, cameras typically produce a RAW image file, which contains all of the digital data read from the sensor. In addition, the camera produces a processed version of the RAW file which is saved in the 8-bit JPEG (Joint Photographic Experts Group) file format. JPEG files are much smaller than the equivalent RAW files due to data compression applied during processing.

\subsection{The Exposure Triangle}

For any particular scene and illumination conditions, the overall exposure of a photograph is determined by three fundamental camera settings; ISO, aperture and shutter speed. Their relative effects are visualised in the exposure triangle (Figure 3 ). 


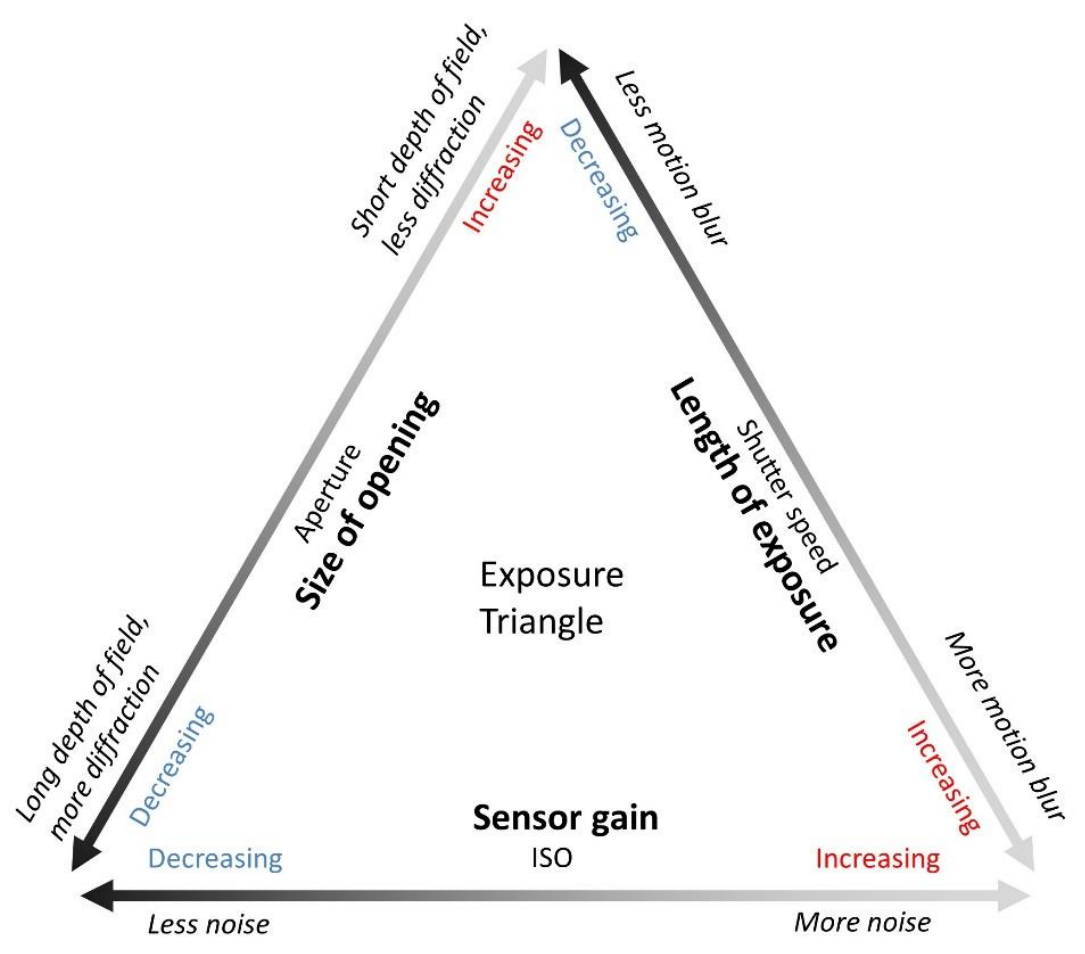

Figure 3. Exposure triangle for image capture. Shades of grey represent apparent brightness in an image.

ISO describes the sensor gain and is determined by the physical characteristics of the sensor and the amplification applied to its output. 'ISO' is derived from the International Organization for Standardization, which promotes a common standard across manufacturers. Higher ISO values (e.g. increasing from ISO100 to ISO800) indicate increased sensor gain, and results in images with greater apparent brightness. However, image noise is also amplified and, at high ISO values, noise can noticeably reduce image quality.

Linked with ISO, the dynamic range of a sensor describes the ratio between the maximum and minimum measurable light intensities (Reinhard et al., 2010). Increasing ISO will decrease the dynamic range. 
Between them, aperture and shutter speed determine the amount of light to which the sensor is exposed during image capture. Aperture describes the size of the light-limiting opening in the lens and is given by an f-number, $N$, for which

$$
N=\frac{f}{D}
$$

where $D$ is the diameter of the opening. Thus, a greater f-number (e.g. f/11) represents a narrower aperture and so less light incident on the sensor than a lower $f$-number (e.g. f/5.6).

The shutter speed determines the length of time the sensor is exposed and is given in seconds (or fractions of a second).

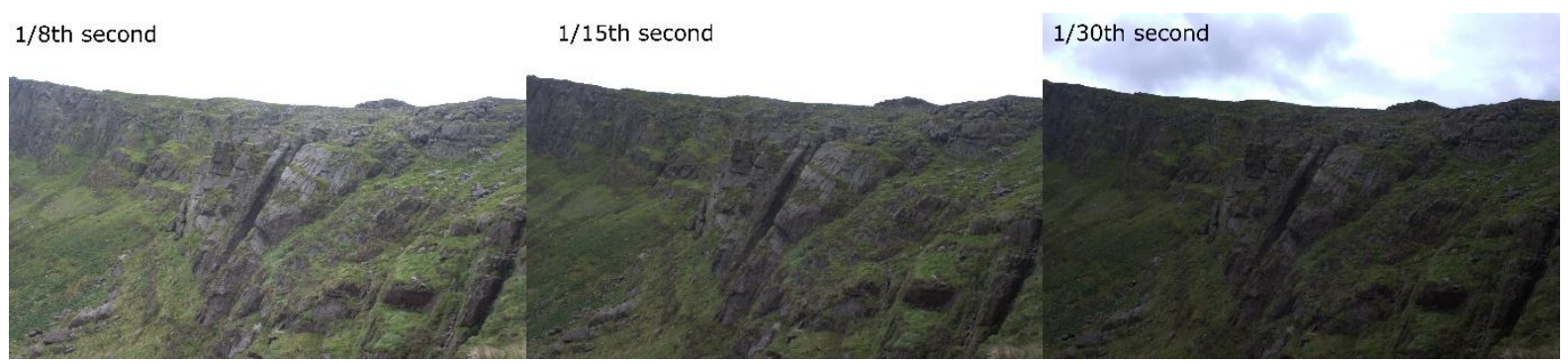

Figure 4. Changes in the shutter speed setting for a scene with all other settings constant. Effective focal length is $35 \mathrm{~mm}$, aperture is $\mathrm{f} / 8$, ISO100, shot on a Canon 500D.

For comparing different images, the combination of aperture and shutter speed is described by the 'exposure value', EV, (Jacobson et al., 2000) for which

$$
E V=\log _{2} \frac{N^{2}}{t}
$$

where $t$ is the shutter speed in seconds. All other conditions being equal, images with the same exposure value should have the same overall brightness.

\subsection{Noise}

The signal from any one photosite is a measure of the number of photons incident on it during the exposure and, as for any measurement, it is subject to noise. Camera electronics are responsible for 
several noise sources (e.g. reading the signal from the sensor, converting to a digital value), and these can be noticeable under low-exposure conditions. However, image noise is usually dominated by 'shot noise' resulting from the random arrival of photons at the sensor. This is a fundamental property of the particulate nature of light, which gives a degree of variability to repeated photon counts from an unvarying light source (Hasinoff, 2014) .
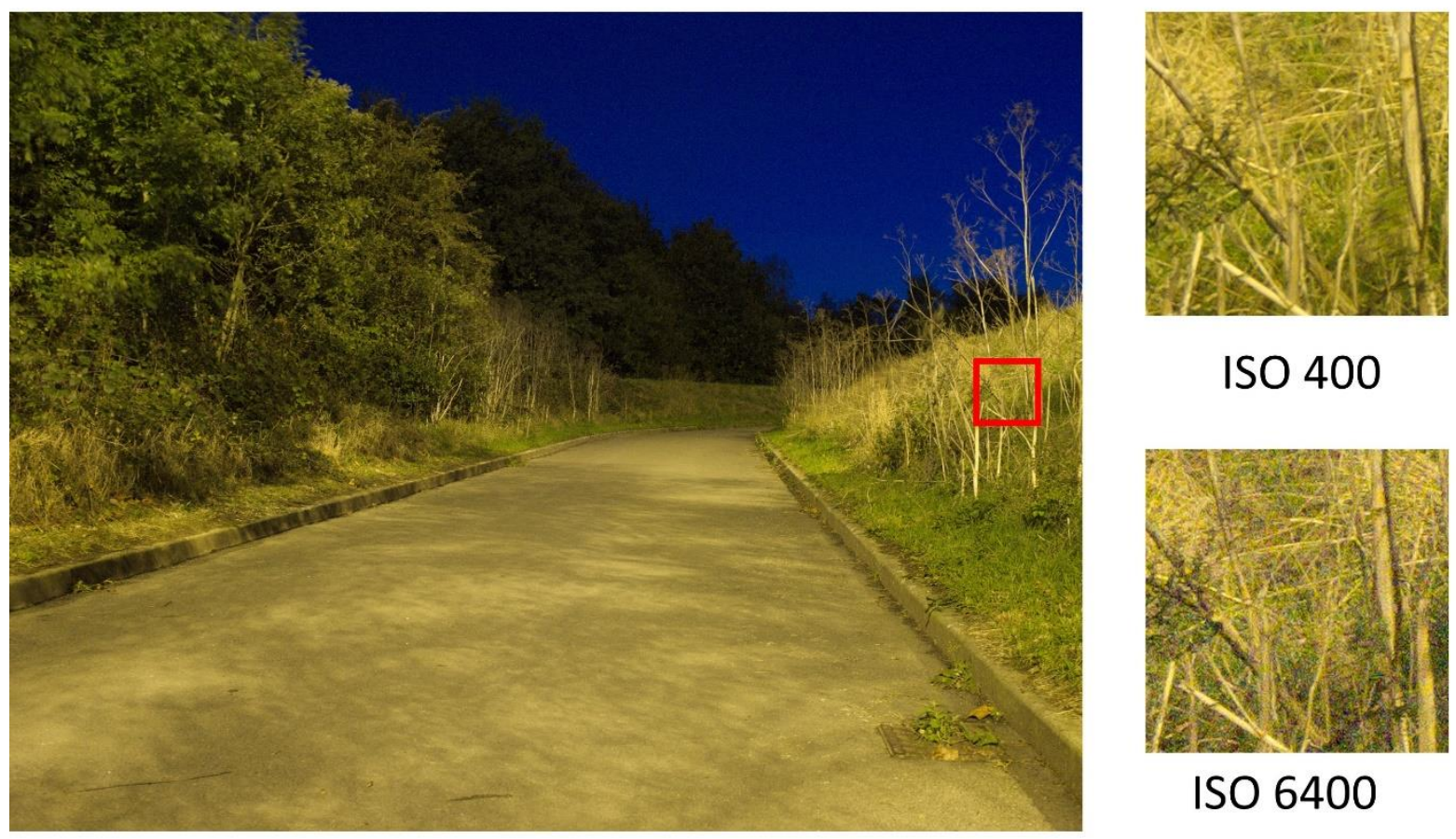

ISO 6400

Figure 5. (a) An image captured at ISO400 with shutter speed of $3.2 \mathrm{~s}$ compared with (b) shooting at ISO6400 with a shutter speed of $1 / 4$ second. The similar overall brightness results from the different ISO values compensating for the different exposure values, but more noise is visible in (b) compared to (a) owing to the higher ISO used.

The effects of shot noise can become particularly acute in dark areas (such as shadows) when the lighting is heterogeneous within an otherwise well-lit scene. One method for reducing shot noise (and so increasing the quality) is to 'expose to the right' (ETTR), which involves overexposing images without saturating the sensor and then subsequently post-processing the image so that it is "well exposed". This post-processing generally involves normalizing the image histograms within a software package, for example Adobe Photoshop (Adobe, 2016), in order to produce an apparently 
well-exposed image. This will modify the original data, so this process should be documented where appropriate. Noise is reported as the signal-to-noise ratio (SNR) in decibels, and ETTR will increase this. 


\section{Cameras}

Cameras suitable for use on low-payload UAVs require a compact design, light weight and must be easy to use. These include, for example, the GoPro series, the Ricoh GR2 and Canon Powershot G10 (e.g. Lucieer et al., 2011, Appendix 1). Compact 'point and shoot' cameras have seen frequent use on UAVs due to their relatively light weight and inbuilt zoom lenses. However, these cameras often have small sensors and very wide-angle lenses which can limit image quality for scientific use (e.g. GoPro series).

As an alternative, interchangeable lens cameras feature the ability to change lenses for different applications. Thus, the camera lens and body are separate components which can be controlled individually depending on the project at hand. However these are generally heavier than compact cameras, which can lead to reduced flight times within a survey.

\subsection{Camera body}

The camera body encloses the sensor, which is often described by its resolution and crop factor. Resolution refers to the number of photosites on the sensor and, thus, to the number of pixels recorded in the captured image. For example, a $3000 \times 2000$ photosite sensor would record 6 million pixels (6 megapixels). The crop factor is a legacy term which dates back to the use of analogue film and describes the size the sensor (Figure 6) relative to that of a 'full frame' camera ( $36 \times 24 \mathrm{~mm}$ ). 'Pixel pitch' describes the physical size of the photosites and is thus related to sensor size and resolution. Cameras with small sensors and high resolutions will have small photosites and so collect fewer photons per photosite (small pixel pitch, lower SNR). This will result in noisier images as ISO will often need to be increased in order to ensure they are correctly exposed. 


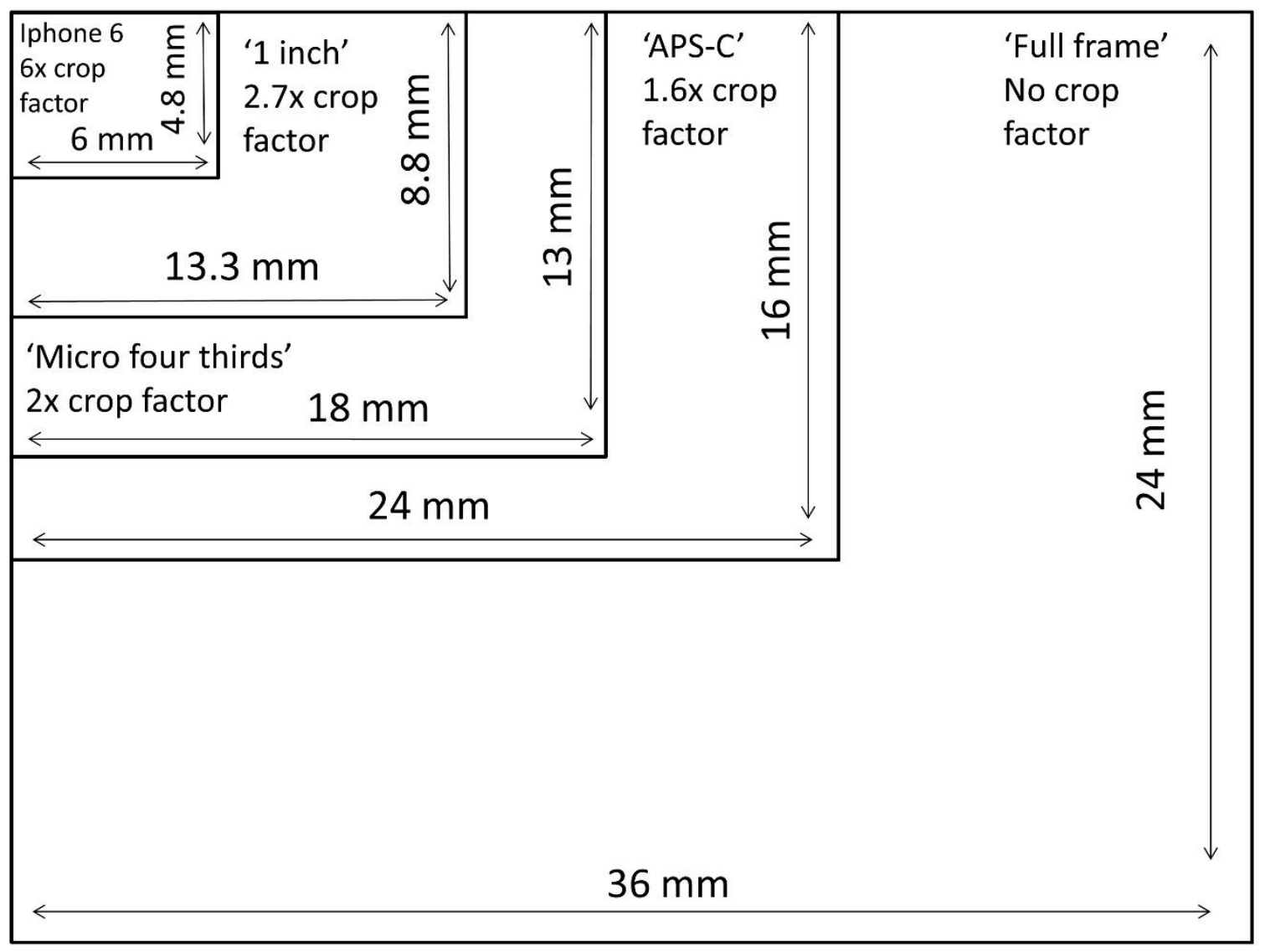

Figure 6. Crop factors for sensor sizes of typical consumer cameras.

Effective focal length (focal length multiplied by crop factor) is frequently used for standardising capture characteristics between cameras of different sensor sizes (and similarly effective aperture, which is aperture multiplied by crop factor). Decreasing the sensor size will increase the effective aperture and focal length. For example, an APS-C sensor (such as that in Canon 550D) will have an effective focal length of $1.6 \times$ that of a full frame sensor (such as that in a Canon 5D) for a lens of the same nominal focal length.

\subsection{Camera lens}

The lens contains the focussing elements to form the image and usually a variable diaphragm (aperture) to limit the size of the opening through which light can pass onto the sensor. Lenses can 
either have a fixed focal length ('prime' lenses) or cover a range of focal lengths ('zoom' lenses). Image quality tends to be better for prime lenses than for zoom lenses because they have fewer moving parts and their optical components will be optimised for a particular focal length, rather than having to work effectively over a range. Longer focal lengths lead to a smaller FOV (Figure 1, 4), with shorter focal lengths often chosen for geoscience UAV campaigns due to the wider FOV.

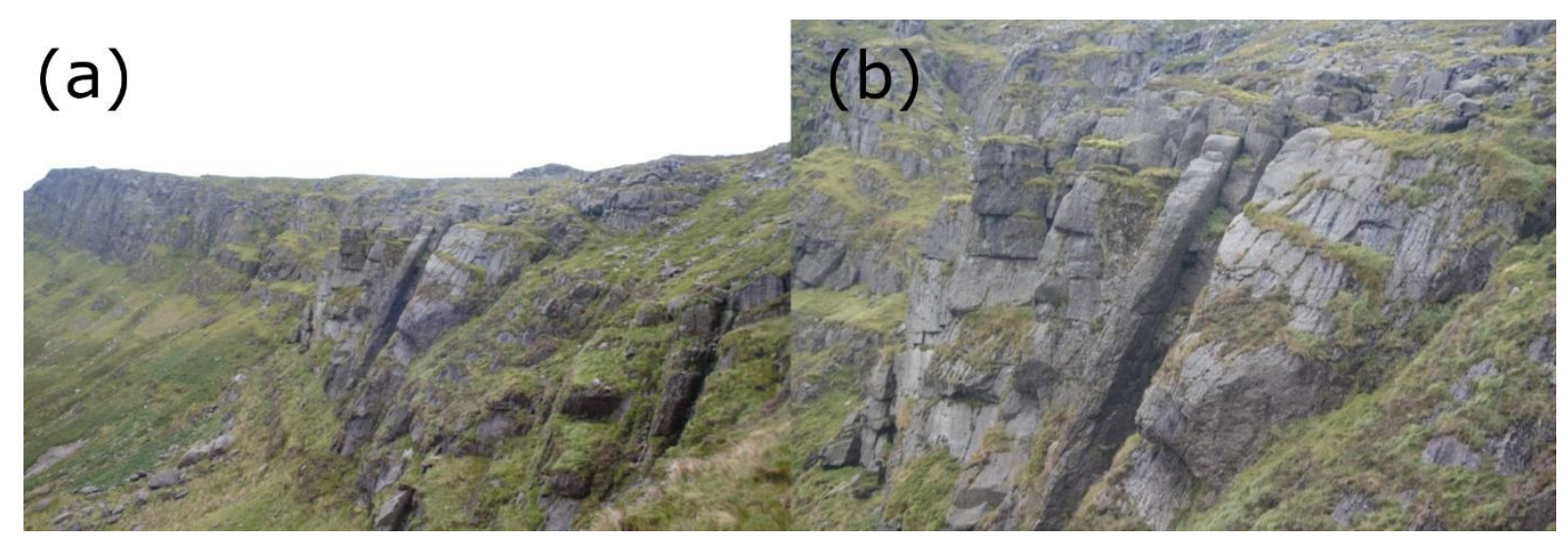

Figure 7. Two images acquired from the same position but with different effective focal lengths $28.8 \mathrm{~mm} \mathrm{(a)} \mathrm{and} 88 \mathrm{~mm}(\mathrm{~b})$, ISO100, aperture f/8 and shutter speed 1/15 s.

A 'perfect' lens would represent straight lines in the scene as straight lines in the image (Figure 8a). However, most lenses are subject to imperfections which result in straight lines being depicted as curves in the image. Such distortions are dominated by radial effects which increase with distance from the centre of the lens and thus are greatest in the corners of the image. Short focal-length lenses tend to display barrel distortion (Figure 8b), which is due to magnification being greater at the centre than at the edges of an image (Anstis, 1998), resulting in straight lines being bowed out towards the image edges (Figure 8b). 


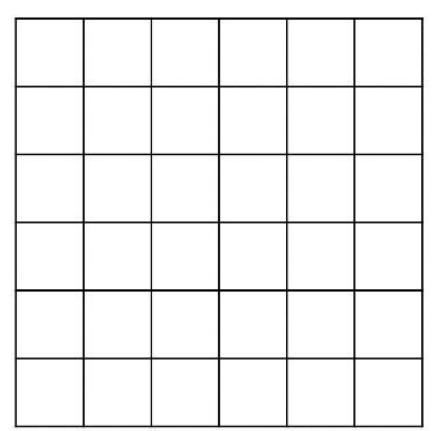

(a)

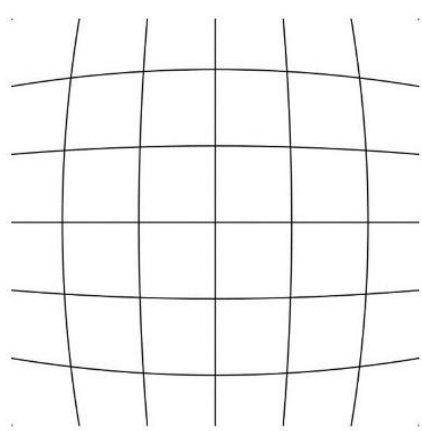

(b)

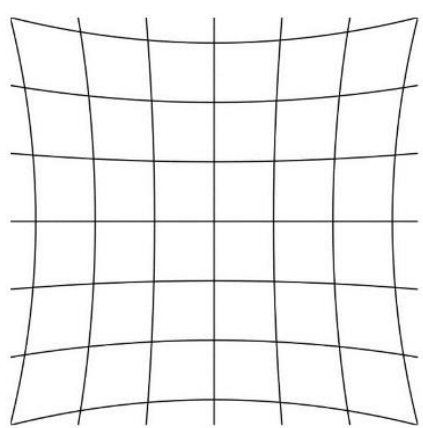

(c)

Figure 8. Idealised examples of lens distortion for (a) no lens distortion, (b) barrel distortion and (c) pincushion distortion.

Pincushion distortion (Figure 8c) is the opposite of barrel distortion, and is typical of telephoto lenses (long focal lengths). Magnification increases at the outer edges of an image, which creates a curving of lines and apparent expansion of features far from the optical axis.

Where distortion is noticeably different for different wavelengths of light, the resulting dispersion is termed chromatic aberration, and can be visible as colour banding around the edges of high contrast features (Fraser, 2013). Chromatic aberration can be avoided by using a monochrome camera if the colour information is not of critical interest, with the added benefit of reduced exposure times due to increased signal per pixel as the light is not filtered for colour (e.g. Rieke-Zapp and Nearing, 2005 using a Kodak DCS1). An alternative is to use only a single colour band; Eisenbeiss (2006) used the green band from images captured using a traditional Bayer CFA as this has a greater number of pixels than red or blue (Figure 2).

The sharpness of the image is affected by both aperture and lens focussing. In an idealised system, a perfectly sharp image is produced when the lens is positioned such that the light from the imaged object is focussed on the sensor - i.e. light rays from a point source intersect exactly on the sensor plane. In real systems, lens imperfections prevent perfect ray intersections on the sensor, with convergence at a small region known as the 'circle of confusion'. However, as long as the circle of confusion is not perceptibly large the object appears to be in focus. 
Moving the object closer or further away from the camera moves the point of ray intersection in front of, or behind, the sensor and thus increases the circle of confusion on the sensor plane (Figure 9).

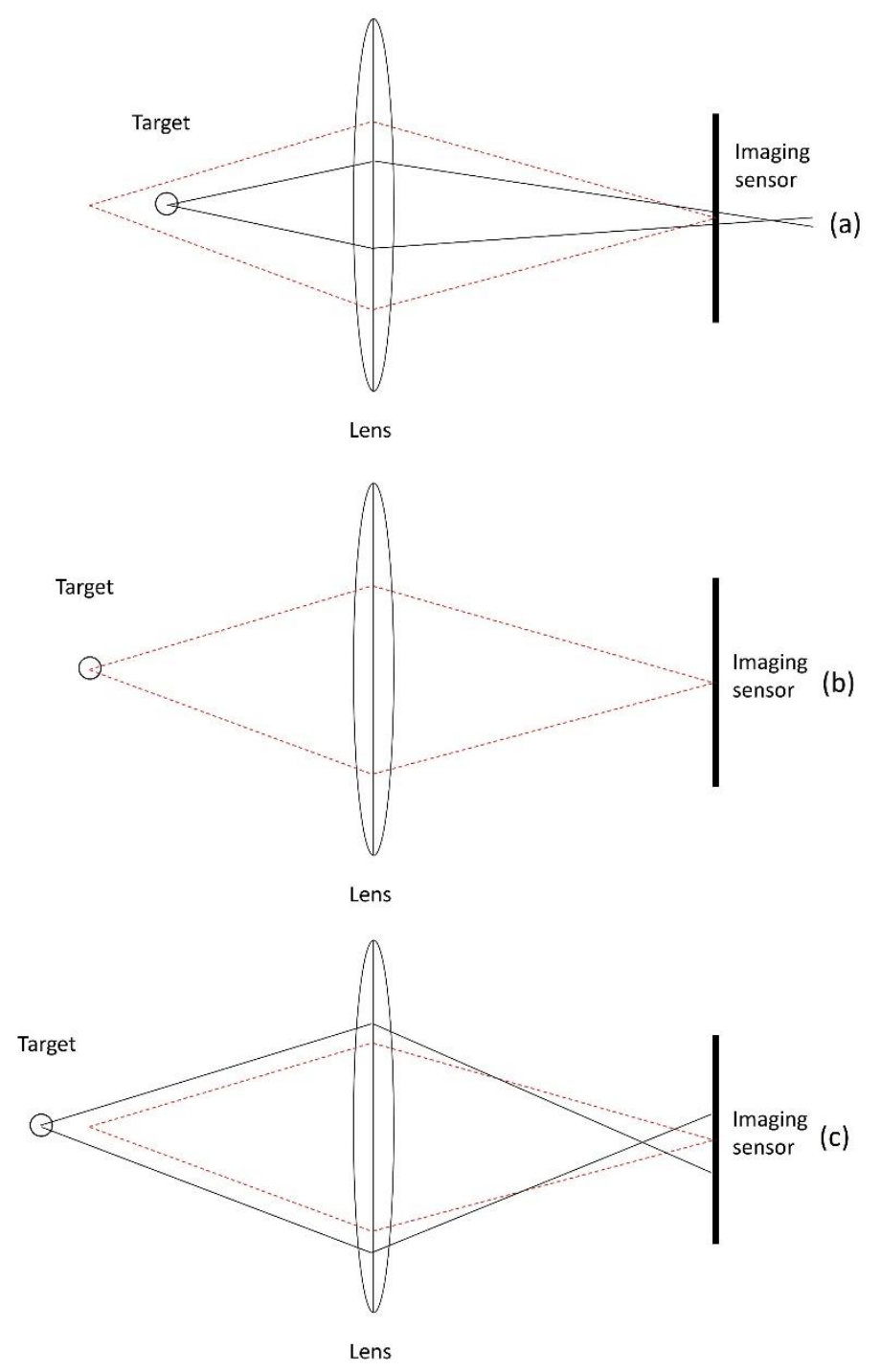

Figure 9. Examples of circles of confusion for targets at different distances from the sensor. Dashed red lines show rays from a target that would be focussed in the image (b). If a target is either too close (a) or too far (c) from the sensor, then rays converge either behind or in front of the sensor respectively, giving perceptible circles of confusion.

The different distances that the object can move, whilst the circle of confusion is still imperceptibly large, gives the 'depth of field' (DoF) - i.e. the range of distances over which objects appear in focus. 
The size of the DoF varies with the lens focal length, aperture and distance for which the lens is focussed. A lens focused far away will give a much greater DoF than the same lens focused at a short distance and smaller apertures (larger f-number) will provide greater DoF than larger apertures (Figure 10).

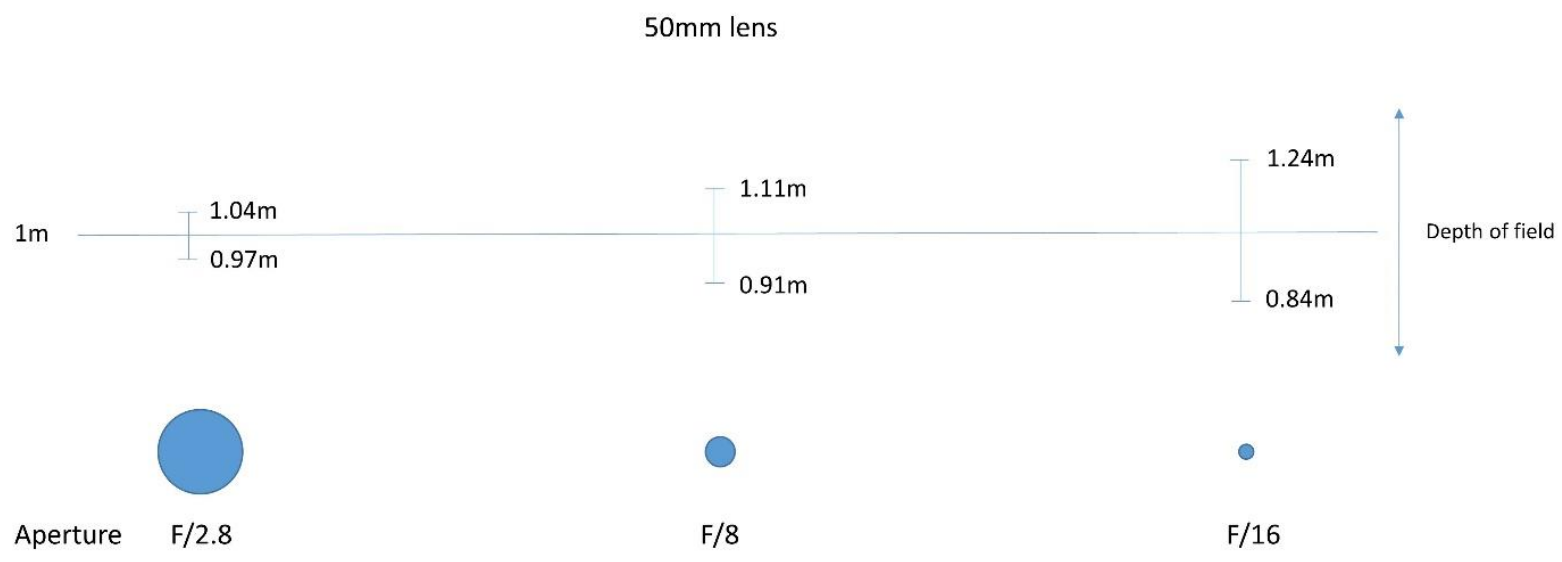

Figure 10. Depth of field at three aperture settings for a $50 \mathrm{~mm}$ focal length lens with an object distance of $1 \mathrm{~m}$. Depth of field increases as aperture becomes smaller, but diffraction effects may appear.

Thus, use of smaller apertures (higher f-numbers) generally gives sharper images due to greater DoF. However, for very small apertures, this advantage becomes limited by diffraction which disperses the light from its original direction of propagation (McGlone, 2013). For a perfect circular aperture, the diffraction pattern produced is dominated by a central area known as an Airy disc (Airy, 1835). The diffraction limit, $d$, is approximated as the size of the Airy disc

$$
\frac{d}{2}=1.22 \lambda \times N
$$

where $\lambda$ is the wavelength of the light and $N$ is the f-stop of the aperture.

For example, a lens with an $\mathrm{f} / 8$ aperture will have an Airy disc $10.7 \mu \mathrm{m}$ in diameter for green light with a wavelength of $0.550 \mu \mathrm{m}$. For a $36 \times 24 \mathrm{~mm}$ sensor (a full-frame sensor) with 6 megapixels, the pixel size is $12 \mu \mathrm{m}$, so the image would not be diffraction limited. However, if the sensor had 16 
megapixels (pixel size $=5.2 \mu \mathrm{m}$ ), it would be diffraction limited. Practically some diffraction is often acceptable to enable a sufficient DoF, ensuring sharpness across a scene.

The resolving capability of a camera system is determined by the quality and configuration of the sensor and lens, and is reported by manufacturers using modulation transfer function (MTF) graphs (Nasse, 2008). MTF graphs represent the imaging sensitivity to straight lines running both parallel ('Sagittal' lines) and perpendicular ('Meridional' lines) from the image centre to the image edge at varying spatial frequencies. The resolving capability for each set of lines is shown relative to the distance from the centre of the image (Figure 11), and provides a standard measure of achievable image sharpness. MTF varies with the aperture of the lens, which should be reported alongside any MTF graph. Some manufacturers (e.g. Nikon) only report the MTF at the widest aperture.

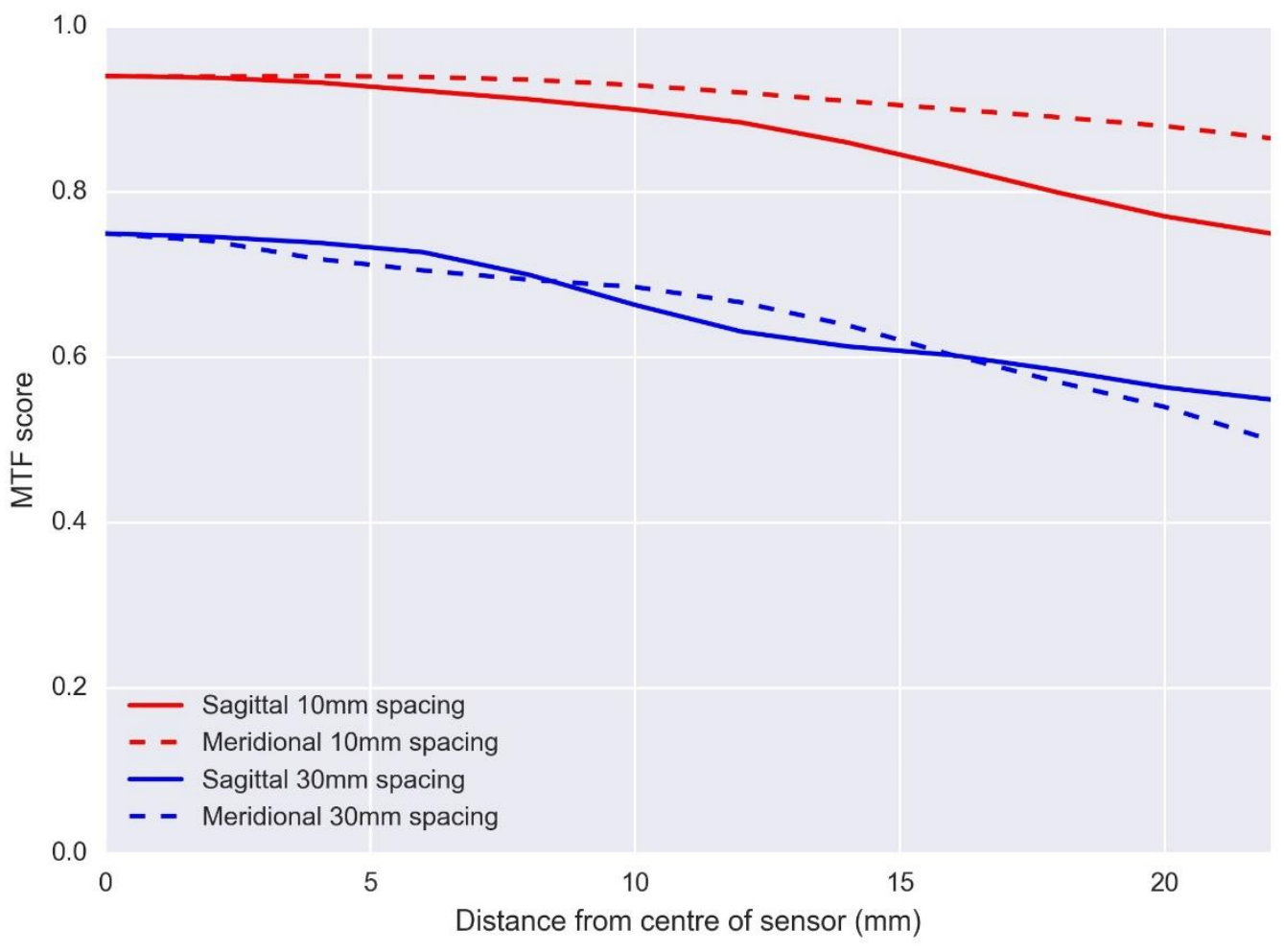

Figure 11. An example MTF chart, illustrating lens resolving capabilities. An MTF score of 1.0 represents perfect contrast preservation (see text for further details).

\subsection{Imaging configuration}


The imaging configuration will define the resolution, as well as the quality of acquired image data.

Flight height, focal length and pixel pitch are the factors which contribute to GSD. GSD can be calculated as

$$
G S D=\frac{2 H \times \arctan \left(S_{d e t}\right)}{2 f} \approx \frac{H \times S_{\text {det }}}{f}
$$

where $H$ is flight height and $S_{\text {det }}$ is the width per pixel on the sensor (pixel pitch). Consequently, GSD can be increased by increasing $f$ or by decreasing $H$. Typical flight heights are between $\sim 10 \mathrm{~m}$ and $1400 \mathrm{~m}$ (e.g. Eltner et al., 2015; Nakano et al., 2014), with limits constrained by the platform being used and government regulation. Consumer-grade multi-rotor UAVs can achieve heights of up to 500 m (e.g. DJI Phantom 3), whilst fixed wing UAVs can fly much higher (e.g. Nakano et al. 2014). Flight velocity is one of the main sources of motion blur in images. The automatic detection and potential correction of blur is a focus of current research (Sieberth et al., 2013). Motion blur, $b$ (in pixels), can be estimated in the forward direction for any aerial survey by

$$
b=\frac{v \times t}{G S D}
$$

where $v$ is the vehicle velocity and $t$ is the shutter speed. Angular motions due to vibrations or vehicle rotations are another factor to consider, but are difficult to avoid unless a stabilised camera mount is used. 


\section{Discussion}

Aerial survey planning should include consideration of imaging configuration (pixel size, focal length, sensor size and flight height) and exposure settings (ISO, aperture, shutter speed, focus and flight velocity) due to their impact on image sharpness and GSD (Summary in Table 1).

\section{Camera specifications $\quad$ Increasing the value gives...}

Pixel size

Sensor size

Focal length

Imaging settings

ISO

Increased apparent brightness, increased noise (can reduce shutter speed
Aperture (Decreased More light incident on sensor, DoF decreases, motion blur may become

f/number) an issue

Shutter Speed (Increased More light incident on the sensor, can reduce ISO but motion blur may

exposure time) become an issue

\section{Flight plan}

Flight height

Flight velocity
Increased GSD, coarser GSD

Larger or quicker surveys, increased risk of motion blur

Table 1. Imaging and survey parameters, and their influence on captured imagery. 
Planning should stem from determining the GSD required to resolve the features of interest in the image, with features recommended to be a minimum of 5 pixels across (this will vary with the nature of the features and image quality), although, in practice, this is often reduced to $\sim 3$ pixels (McGlone, 2013; Torralba, 2009). If 3-D topographic data are a required product, then the required GSD will also depend on the topographic spatial resolution and precision requirements, with smaller GSDs generally required in order to resolve features usefully in 3-D. Precision estimates are more complex to determine, because they are controlled by a wide range of factors such as the overall geometry of the camera positions (the 'image network geometry'); GSD plays a role through scaling photogrammetric error into the real-world coordinate system. Previously, the precision achieved over a variety of SfM surveys and camera types has been characterised as dimensionless ratios against viewing distance (which is flight height for UAV surveys), giving values of orders 1:500 to 1:5,000 (James and Robson, 2012; Smith and Vericat, 2015).

GSD is controlled by the combination of focal length, flight height and the size of the sensor (Equation 5). Effective focal lengths of 18-24 $\mathrm{mm}$ are frequently used for aerial campaigns (Appendix 1), partly because lower flight heights require a wider FOV for aerial coverage and partly because longer focal length lenses are generally heavier. Greater flight height will give a larger image footprint but will increase GSD and decrease flight time because ascending to higher altitudes will consume power. Thus, we recommend shorter effective focal length lenses $(24-35 \mathrm{~mm})$ and to select the appropriate altitude for the desired GSD.

GSD also depends on the pixel pitch on the camera's sensor. Ensuring sensor size is the maximum that is practically possible will lead to larger pixel pitches, a shorter effective focal length and reduced diffraction effects with better image quality. This will also reduce the constraints on the imaging settings required to capture sharp, well exposed imagery. Point and shoot cameras typically have smaller sensors (e.g. Sony Cybershot RX100 at $13.2 \mathrm{~mm}$ x $8.8 \mathrm{~mm}$ ), and smartphones smaller again (e.g. iPhone 6 at $6 \mathrm{~mm} \times 4.8 \mathrm{~mm}$ ), which will ultimately limit the imaging settings within a 
given study. These cameras will perform worse under low-light conditions (due to relatively low SNR) and those where vibrations are high (due to their low weight).

Next, we consider the exposure settings. The camera's sensor will have a dynamic range specific to each ISO value, and so allow the calculation of the range of signal intensities capable of being captured in an image. The results of benchmarking tests are often publically available (DxOMark, 2016). ISO should ideally be set to the minimum value required to ensure good exposure, in order to maximise the dynamic range that can be captured. Typical ISOs used for aerial image capture are around 100-800; shooting at higher values will lead to a smaller dynamic range and increase noise within each image. This noise will also in turn have negative impacts on image processing products such as orthophotos.

The selected ISO value affects the choice of shutter speed, and both must be determined appropriately to ensure a good exposure with little motion blur, depending on flight velocity. To minimise blur the distance travelled by the platform during an exposure should be $<1.5$ times the GSD (Ordnance survey, 2015). In the literature (Appendix 1) shutter speeds range from between $1 / 250 \mathrm{~s}$ to $1 / 1000 \mathrm{~s}$ with slower speeds increasing the likelihood of detrimental motion blur. Depending on the size of the area to be surveyed, as well as desired image overlap and camera specifications, shutter speed constraints will change. For example, to cover a larger area for a given configuration, a higher velocity would be required. This will in turn reduce the minimum exposure time ( $\mathrm{t}$ in equation 6 ) to keep blur below 1.5 times GSD. Thus, ISO will have to be increased for the shorter shutter speed.

Both noise and blur will affect the accuracy of image registration, the first part of the SfM workflow. Sieberth et al. (2014) report that 'small camera displacements have a significant impact on the accuracy of subsequent calculations and processes', their tests showing that for automatic target detection and localization of the target centres, accuracy rapidly drops off as motion blur is 
increased. This localisation ambiguity will in turn affect the accuracy of derivative products, such as SfM derived models (Harwin and Lucieer, 2012).

Lastly, aperture principally depends on the DoF required and the distance to the scene. DoF will, in turn, depend on the distance the lens is focused. For campaigns with flight heights $>20 \mathrm{~m}$, effective aperture can be fixed at a medium setting (f/5.6-f/11). This limits the effects of diffraction, allows for a greater depth of field and is often where a lens will be sharpest (based upon MTF graphs).

Focus should be set last, and such that the depth of field for the combination of object distance, aperture and focal length ensures all features within the image are sharp. For most UAV flights (apart from missions conducted at very low flight heights) focus will be set at infinity.

We can utilise this information to accurately plan for image quality in a survey by calculating the effects of each parameter on expected products. We firstly do this in a theoretical framework, and subsequently discuss two real world examples, and the limitations encountered.

\subsection{Example 1: Survey planning}

As a worked example of planning the imaging characteristics for a survey, suppose we want to capture features of interest that are a minimum of $100 \mathrm{~mm}$ in size, using a Ricoh GR $(23.98 \times 16.41$ $\mathrm{mm}$ sensor size, 16.2 megapixels, $4.8 \mu \mathrm{m}$ pixel pitch), with a focal length (f) of $18.3 \mathrm{~mm}$ (effective focal length $28 \mathrm{~mm}$ ). We would begin by calculating the required GSD as $0.02 \mathrm{~m}$ (a fifth of the minimum feature; Table 2). 


\begin{tabular}{ll}
\hline Inputs & Value \\
\hline Size of features $(\mathrm{mm})$ & 100 \\
GSD required $(\mathrm{mm})$ & 20 \\
Pixel Pitch $(\mathrm{mm})$ & 0.0048 \\
Focal Length $(\mathrm{mm})$ & 18.3 \\
Shutter Speed $(\mathrm{s})$ & 0.002 \\
Aperture & $\mathrm{f} / 5.6$ \\
\hline
\end{tabular}

Table 2. Inputs for each parameter in the worked example.

The flight height $(\mathrm{H})$ can then be calculated using equation 5 , with an $18.3 \mathrm{~mm}$ focal length and 4.8 $\mu \mathrm{m}$ pixel pitch, to give $76.25 \mathrm{~m}$.

$$
\begin{aligned}
& 0.02 \mathrm{~m} \approx \frac{H \times\left(4.8 \times 10^{-6} \mathrm{~m}\right)}{0.0183 \mathrm{~m}} \\
& H=76.25 \mathrm{~m}
\end{aligned}
$$

There are many examples of software which will perform these calculations given the relevant flight height, sensor information and lens focal length (e.g. Aerial Survey Base 2016).

For this camera, at an aperture $(\mathrm{N})$ of $\mathrm{f} / 5.6$ we use equation 4 to calculate the diffraction limit, $d$ :

$$
\begin{aligned}
& \frac{d}{2}=1.22\left(5.5 \times 10^{-7}\right) \times 5.6 \\
& d=7.5 \times 10^{-6} \mathrm{~m}
\end{aligned}
$$

This indicates that images will be diffraction limited due to $d$ being larger than the pixel pitch, which will cause some slight image degradation. Next, we would calculate the imaging configuration to 
ensure blur is kept to a minimum. Setting 1.5 pixels as the limit of tolerable blur and using a flight height $(H)$ of $76.25 \mathrm{~m}$ with a shutter speed (s) of $1 / 500 \mathrm{~s}$ in equation 6 , we calculate flight velocity (v):

$$
\begin{aligned}
& 1.5<\frac{v \times 0.002}{0.02} \\
& v<15 \mathrm{~m} / \mathrm{s}
\end{aligned}
$$

$v$ needs to be less than $15 \mathrm{~m} / \mathrm{s}$ to ensure this constraint is met. We can use this information to decide the ISO, or alternatively use Auto-ISO, to automatically optimize ISO to maintain good exposure. Depending on the size of the area to be surveyed, we could decrease shutter speed or increase ISO to allow a faster flight velocity. In blustery conditions where angular motion is likely to be significant, we advise both reducing the shutter speed and increasing the ISO to compensate. Whilst this will increase noise, sharp but noisier images are more desirable than blurry ones.

\subsection{Example 2: Soil rill survey}

Setting

Number of images 100

Sensor size

$7.4 \mathrm{~mm} \times 5.5 \mathrm{~mm}$

$23.6 \mathrm{~mm} \times 15.8 \mathrm{~mm}$

Pixel pitch

$2 \mu \mathrm{m}$

$5.5 \mu \mathrm{m}$

Focal length

$5.1 \mathrm{~mm}$ (25 mm effective focal length)

$28 \mathrm{~mm}$ (42 $\mathrm{mm}$ effective focal length)

Aperture

$f / 4$

\section{Braided river survey}

(Example 2, Williams et al., 2014)
Not reported

Not reported 


$\begin{array}{lll}\text { Shutter speed } & \text { Not reported } & \text { Not reported } \\ \text { ISO } & \text { Not reported } & \text { Not reported } \\ \text { Flight height } & 10 \mathrm{~m} & 1200 \mathrm{~m} \\ \text { Flight velocity } & \text { Static (Dwelled at position) } & \text { Not reported } \\ & & \\ \text { GSD } & 4 \mathrm{~mm} & 0.2 \mathrm{~m}\end{array}$

Table 3. Reported camera and imaging characteristics for two example surveys.

Eltner et al. (2015) undertook a multi-temporal study of soil erosion rills of 2-4 cm in depth and 17$24 \mathrm{~cm}$ in width for a $20 \mathrm{~m} \times 30 \mathrm{~m}$ area. The authors achieved a $4 \mathrm{~mm}$ GSD using a Panasonic Lumix DMC-LX3 with a $5.1 \mathrm{~mm}$ focal length ( $25 \mathrm{~mm}$ effective focal length), aperture of $\mathrm{f} / 4$, and flying at a height of $10 \mathrm{~m}$. The identification of rills within the image data was straightforward because the GSD was much smaller than the scale of the features themselves. If the task was purely 2-D rill detection, the authors could have planned for a GSD of $3 \mathrm{~cm}$, which would have allowed a greater flight height or shorter focal length, resulting in a larger footprint for each image.

With the aperture at $\mathrm{f} / 4$, the Airy disc cast at $550 \mathrm{~nm}$ will have a diameter of (equation 4):

$$
\begin{aligned}
& \frac{d}{2}=1.22\left(5.5 \times 10^{-7}\right) \times 4 \\
& d=5.37 \times 10^{-6} \mathrm{~m} .
\end{aligned}
$$


This indicates that some diffraction effects will be present because the Airy disc was greater than the pixel pitch of the camera $(2 \mu \mathrm{m})$. This could have been mitigated by using a camera with a larger pixel pitch.

The authors report using an active stabilization system which records images from a static position at each image location, thus blur is considered to be minimal in this context. The ISO used was not reported. Blur is expected to have had minimal impact on the results of the study, which involved 3D reconstruction of the rill topography.

\subsection{Example 3: Braided river survey}

Williams et al. (2014) studied a $2.5 \mathrm{~km}$ reach of braided riverbed using a standard manned helicopter in order to acquire images for the construction of a hyperscale (sub-metre) terrain model (studying a river with gravel $\sim 20 \mathrm{~mm}$ in size). The authors reported a $20 \mathrm{~cm}$ GSD using a Nikon D90 with a 28 $\mathrm{mm}$ focal length (42 mm effective focal length) flying at a height $1200 \mathrm{~m}$. The aperture used was not reported. The acquired image data was to be used in the generation of a 3-D terrain model using SfM photogrammetry.

Given the provided information, we can derive the GSD from equation 5 as:

$$
G S D=\frac{1200 \times\left(5.5 \times 10^{-6}\right)}{0.028}=23.5 \mathrm{~cm}
$$

which is broadly equivalent to the reported value $(20 \mathrm{~cm})$. Neither flight velocity or shutter speed were reported and so the effect of motion blur cannot be ascertained. Considering the camera was set to use an intervalometer (one image to be acquired every $5 \mathrm{~s}$ ), the platform was likely moving during exposures.

At a flying height of $1200 \mathrm{~m}$, the image footprint is $1010 \mathrm{~m} \times 672 \mathrm{~m}$. We can estimate the flight velocity by ensuring sufficient overlap for high redundancy orthophotos ( $80 \%$ forelap between images). Assuming a landscape orientation, using equation 7: 


$$
\begin{aligned}
& v=\frac{\text { Image footprint width } \times(1-\text { forelap })}{\text { Intervalometer time interval }}(7) \\
& v=\frac{672 \times(1-0.8)}{5}=26.9 \mathrm{~m} / \mathrm{s}
\end{aligned}
$$

At $26.9 \mathrm{~m} / \mathrm{s}$, we can calculate the maximum shutter speed which will keep $b$ below 1.5 using equation 6:

$$
\begin{aligned}
& 1.5<\frac{26.9 \times t}{0.235} \\
& t=0.013 \mathrm{~s}
\end{aligned}
$$

Given $t$ is relatively long, we would have freedom to increase flight velocity and reduce $t$ in order to increase the total survey area, bearing in mind the forelap will be reduced. Furthermore we could increase the f-number to ensure sharpness is maximised (based on MTF charts) and subsequently decrease $t$ if the images are underexposed.

\subsection{The Future: Reporting image metadata for surveys}

The examples presented in this paper show the limited information that is available in published work concerning the image data collected as part of photo-based surveys. Yet this information is critical to ascertaining the quality of the input image data which, fundamentally, represents the underpinning raw data, and can impact the efficacy of the derived outputs. As a result, we believe it is essential that this information is reported and here we present a series of recommendations for the geoscience community.

Ideally, all image data should be captured using the RAW file format and these should be made available in an open access repository under a Creative Commons license with links provided in published work (e.g. James and Robson, 2012). Where this is not possible, all pertinent image metadata should be reported in a supplementary spreadsheet that accompanies the manuscript and is available as supplementary materials either at the journal website or within a data repository. Key image metadata to report include the camera make and model (and lens if appropriate), filename, 
ISO, shutter speed, aperture and focal length. Additionally, and where available, the latitude, longitude and elevation (noting datum) should also be reported. In addition, summary survey information should be included within a paper reporting the size of the study area, approximate GSD, percentage forelap/sidelap, number of images, camera and lens characteristics (including sensor size, sensor resolution, pixel pitch, focal length), crop factor, UAV model, flight height and flight velocity. Summary statistics (modal, minimum and maximum values for ISO, shutter speed and aperture) of the spreadsheet metadata could accompany this to provide an overview of the image data.

Nearly all digital cameras support the EXIF (EXchangeable Image File) standard and embed metadata as header information into the digital file. This information can be automatically extracted using, for example, ExifTool (ExifTool, 2016), and saved to a spreadsheet. The accompanying spreadsheet is provided as an example using images which are publically available (OpenDroneMap, 2016). In addition, Tables 4 and 5 report survey and image data respectively.

\section{EXIF Summary}

\begin{tabular}{ll}
\hline Number of images & 12 \\
Camera model & Canon EOS DIGITAL REBEL XSi \\
Lens model & Built-in \\
Image resolution & $4272 \times 2848$ pixels \\
Crop factor & 1.615 \\
Approximate sensor size & $22.286 \mathrm{~mm} \times 14.857 \mathrm{~mm}$ \\
Pixel pitch & $5.217 \mu \mathrm{m}$ \\
Flight velocity & $10 \mathrm{~m} / \mathrm{s}$ (Idealised) \\
Flight height & $100 \mathrm{~m}$ (Idealised) \\
GSD & $0.015 \mathrm{~m}$
\end{tabular}

Table 4. A summary of EXIF information from a sample of OpenDroneMap (2016) imagery. 


\begin{tabular}{lrrr} 
Parameter & Mode & \multicolumn{1}{l}{ Min } & \multicolumn{1}{l}{ Max } \\
& & & \\
\hline Shutter speed (s) & 0.00125 & 0.00125 & 0.00125 \\
F number & 5 & 3.5 & 5.6 \\
ISO & 400 & 400 & 400
\end{tabular}

Table 5. Imaging parameter statistics for the sample of OpenDroneMap (2016) imagery.

From this metadata, the f-number for when diffraction will become apparent can be calculated using equation 4:

$\frac{5.2 \times 10^{-7}}{2}=1.22\left(5.5 \times 10^{-7}\right) \times N$

$N=3.887$

The shutter speed required to keep motion blur to less than 1.5 pixels, using an assumed flight height of $100 \mathrm{~m}$ and velocity of $10 \mathrm{~m} / \mathrm{s}$ can be calculated using equation 6 :

$$
\begin{aligned}
& 1.5=\frac{10 \times t}{0.015} \\
& t=0.0022 \mathrm{~s}
\end{aligned}
$$

For this survey the images were not diffraction limited and as the shutter speed was faster than $0.0022 \mathrm{~s}$ motion blur should be limited. To help support confidence in derived products, we encourage examples of the image data used to be provided within publications, with excerpts sufficiently enlarged to enable a visual assessment of image quality (e.g. James and Robson, 2012). 


\section{Conclusion}

We have provided a brief overview of the physical principles of digital image capture and how these are controlled through aperture, shutter speed and ISO to produce a "well exposed" image. The choice of camera body and lens places constraints on the capture process, with UAV flight height and speed determining the positioning of the whole system. Careful consideration of imaging settings will allow UAV users to maximise the quality of images acquired when performing aerial surveys, and will also increase the reproducibility. Image capture will often require trade-offs between all of the settings presented, and we provide a planning workflow for optimising choices in order to find the best solution for the objectives of the survey. This begins with the minimum feature size that needs to be detected, allowing the calculation of the ground sample distance (GSD). Based upon the camera and lens combination, the flight height to achieve this can be specified and then the flight speed to minimise motion blur.

Given the number of geoscientists using UAVs for aerial surveys, the optimisation of survey specification will maximise the probability of high quality image capture. However, it is critical that researchers report full survey and image information to allow independent assessment of image quality and the potential for future reproducibility. We present a series of recommendations for future workers in the reporting of metadata. 


\section{References}

Aber JS, Aber SW and Pavri F (2002) Unmanned small format aerial photography from kites acquiring large-scale, high-resolution, multiview-angle imagery. International Archives of Photogrammetry Remote Sensing and Spatial Information Sciences 34(1): 1-6.

Adobe (2016) Adobe by Adobe. Available from: www.adobe.com Last accessed 07/11/2016.

Aerial Survey Base (2016) GSD calculator by Aerial Survey Base. Available from: https://www.aerialsurvey-base.com/gsd-calculator Last accessed 07/11/2016.

Ahmad A and Chandler J (1999) Photogrammetric capabilities of the Kodak DC40, DCS420 and DCS460 digital cameras. The Photogrammetric Record 16(94): 601-615.

Airy GB (1835) On the diffraction of an object-glass with circular aperture. Transactions of the Cambridge Philosophical Society 5: 283-283.

Anderson K and Gaston KJ (2013) Lightweight unmanned aerial vehicles will revolutionize spatial ecology. Frontiers in Ecology and the Environment 11(3): 138-146.

Anstis S (1998) Picturing peripheral acuity. Perception-London- 27: 817-826.

Bemis SP, Micklethwaite S, Turner D, James MR, Akciz S, Thiele ST, et al. (2014) Ground-based and UAV-Based photogrammetry: A multi-scale, high-resolution mapping tool for structural geology and paleoseismology. Journal of Structural Geology 69, Part A(0): 163-178.

Butler JB, Lane SN and Chandler JH (1998) Assessment of Dem Quality for Characterizing Surface Roughness Using Close Range Digital Photogrammetry. The Photogrammetric Record 16(92): 271-291. 
Chandler J, Lane S and Ashmore P (2000) Measuring river-bed and flume morphology and parameterising bed roughness with a Kodak DCS460 digital camera. International Archives of Photogrammetry and Remote Sensing 33(B7/1; PART 7): 250-257.

Chandler J and Padfield C (1996) Automated digital photogrammetry on a shoestring. The Photogrammetric Record 15(88): 545-559.

Chandler J, Ashmore P, Paola C, Gooch M and Varkaris F (2002) Monitoring river-channel change using terrestrial oblique digital imagery and automated digital photogrammetry. Annals of the Association of American Geographers 92(4): 631-644.

Civil Aviation Authority (2010) Unmanned Aircraft System Operations in UK Airspace-Guidance (CAP 722). Civil Aviation Authority, London.

Clodius WB (2007) Multispectral and Hyperspectral Image Processing, Part 1: Initial Processing. Taylor \& Francis, 1390-1405.

Dean C, Warner TA and McGraw JB (2000) Suitability of the DCS460c colour digital camera for quantitative remote sensing analysis of vegetation. ISPRS Journal of Photogrammetry and Remote Sensing 55(2): 105-118.

d'Oleire-Oltmanns S, Marzolff I, Peter KD and Ries JB (2012) Unmanned Aerial Vehicle (UAV) for monitoring soil erosion in Morocco. Remote Sensing 4(11): 3390-3416.

DxOMark (2016) DxOMark by DxO. Available from: www.dxomark.com Last accessed 07/11/2016.

Eisenbeiss $\mathrm{H}$ (2006) Applications of photogrammetric processing using an autonomous model helicopter. International Archives of Photogrammetry, Remote Sensing and Spatial Information Sciences 36. 
Eltner A, Mulsow C and Maas H (2013) Quantitative measurement of soil erosion from tls and uav data. ISPRS-International Archives of the Photogrammetry, Remote Sensing and Spatial Information Sciences 1(2): 119-124.

Eltner A, Baumgart P, Maas H and Faust D (2015) Multi-temporal UAV data for automatic measurement of rill and interrill erosion on loess soil. Earth Surface Processes and Landforms 40(6): 741-755.

ExifTool (2016) ExifTool by Phil Harvey. Available from: http://owl.phy.queensu.ca/ phil/exiftool/ Last accessed 07/11/2016.

Fritz A, Kattenborn T and Koch B (2013) UAV-Based Photogrammetric Point Clouds-Tree Stem Mapping In Open Stands In Comparison To Terrestrial Laser Scanner Point Clouds. International Archives of the Photogrammetry, Remote Sensing and Spatial Information Sciences, XL 1: W2.

Geipel J, Link J and Claupein W (2014) Combined spectral and spatial modeling of corn yield based on aerial images and crop surface models acquired with an unmanned aircraft system. Remote Sensing 6(11): 10335-10355.

Gupta RP (2013) Remote Sensing Geology. : Springer Science \& Business Media.

Harwin S and Lucieer A (2012) Assessing the accuracy of georeferenced point clouds produced via multi-view stereopsis from unmanned aerial vehicle (UAV) imagery. Remote Sensing 4(6): 15731599.

Hasinoff SW (2014) Photon, Poisson Noise. In: Anonymous Computer Vision. : Springer, 608-610.

Hubel PM, Liu J and Guttosch RJ (2004) Spatial Frequency Response of Color Image Sensors: Bayer Color Filters and Foveon X3. : International Society for Optics and Photonics. 
Hunt ER, Hively WD, Fujikawa SJ, Linden DS, Daughtry CS and McCarty GW (2010) Acquisition of NIRgreen-blue digital photographs from unmanned aircraft for crop monitoring. Remote Sensing 2(1): 290-305.

Immerzeel W, Kraaijenbrink P, Shea J, Shrestha A, Pellicciotti F, Bierkens M, et al. (2014) Highresolution monitoring of Himalayan glacier dynamics using unmanned aerial vehicles. Remote Sensing of Environment 150: 93-103.

ISO I (1997) 12232: Photography-Electronic Still Picture Cameras: Determination of ISO Speed. International Organization for Standardization, Geneva, Switzerland.

Jacobson R, Ray S, Attridge GG and Axford N (2000) Manual of Photography. : Taylor \& Francis.

James MR and Robson S (2012) Straightforward reconstruction of 3D surfaces and topography with a camera: Accuracy and geoscience application. Journal of Geophysical Research: Earth Surface 117, F03017.

Kraus K (2007) Photogrammetry: Geometry from Images and Laser Scans. : Walter de Gruyter.

Lane S, James T and Crowell M (2000) Application of digital photogrammetry to complex topography for geomorphological research. The Photogrammetric Record 16(95): 793-821.

Lillesand T, Kiefer RW and Chipman J (2014) Remote Sensing and Image Interpretation. : John Wiley \& Sons.

Lisein J, Pierrot-Deseilligny M, Bonnet S and Lejeune P (2013) A photogrammetric workflow for the creation of a forest canopy height model from small unmanned aerial system imagery. Forests 4(4): 922-944. 
Lucieer A, Turner D, King DH and Robinson SA (2014a) Using an Unmanned Aerial Vehicle (UAV) to capture micro-topography of Antarctic moss beds. International Journal of Applied Earth Observation and Geoinformation 27: 53-62.

Lucieer A, Jong SM and Turner D (2014b) Mapping landslide displacements using Structure from Motion (SFM) and image correlation of multi-temporal UAV photography. Progress in Physical Geography 38: 97-116.

Lucieer A, Robinson S and Turner DJ (2011) Unmanned Aerial Vehicle (UAV) Remote Sensing for Hyperspatial Terrain Mapping of Antarctic Moss Beds based on Structure from Motion (SfM) point clouds. Proceedings of the 34th International Symposium on Remote Sensing of Environment (ISRSE34).

Marzolff I and Poesen J (2009) The potential of 3D gully monitoring with GIS using high-resolution aerial photography and a digital photogrammetry system. Geomorphology 111(1): 48-60.

Mason S, Rüther H and Smit J (1997) Investigation of the Kodak DCS460 digital camera for small-area mapping. ISPRS Journal of Photogrammetry and Remote Sensing 52(5): 202-214.

McGlone JC (2013) Manual of Photogrammetry. : American Society for Photogrammetry and Remote Sensing.

Nakano T, Kamiya I, Tobita M, Iwahashi J and Nakajima H (2014) Landform monitoring in active volcano by UAV and SfM-MVS technique. ISPRS-International Archives of the Photogrammetry, Remote Sensing and Spatial Information Sciences 1: 71-75.

Nasse H (2008) How to read MTF curves. Carl Zeiss Camera Lens. Available from: https://www.zeiss.com/content/dam/Photography/new/pdf/en/cln_archiv/cln30_en_web_spe cial_mtf_01.pdf Last accessed 07/11/2016. 
Niethammer U, Rothmund S, James M, Travelletti J and Joswig M (2010) UAV-based remote sensing of landslides. International Archives of Photogrammetry, Remote Sensing and Spatial Information Sciences 38(Part 5): 496-501.

OpenDroneMap (2016) OpenDroneMap Pacifica Dataset. Available from: https://github.com/OpenDroneMap/odm_data_pacifica Last accessed 07/11/2016.

Ouedraogo MM, Degra A, Debouche C and Lisein J (2014) The evaluation of unmanned aerial system-based photogrammetry and terrestrial laser scanning to generate DEMs of agricultural watersheds. Geomorphology 214(0): 339-355.

Puliti S, Ørka HO, Gobakken T and Næsset E (2015) Inventory of small forest areas using an unmanned aerial system. Remote Sensing 7(8): 9632-9654.

Pyle C, Richards K and Chandler J (1997) Digital photogrammetric monitoring of river bank erosion. The Photogrammetric Record 15(89): 753-764.

Reinhard E, Heidrich W, Debevec P, Pattanaik S, Ward G and Myszkowski K (2010) High Dynamic Range Imaging: Acquisition, Display, and Image-Based Lighting. : Morgan Kaufmann.

Remondino F and Fraser C (2006) Digital camera calibration methods: considerations and comparisons. International Archives of Photogrammetry, Remote Sensing and Spatial Information Sciences 36(5): 266-272.

Rieke-Zapp D and Nearing MA (2005) Digital close range photogrammetry for measurement of soil erosion. Photogrammetric Record 20: 69-87.

Rippin DM, Pomfret A and King N (2015) High resolution mapping of supra-glacial drainage pathways reveals link between micro-channel drainage density, surface roughness and surface reflectance. Earth Surface Processes and Landforms 40(10): 1279-1290. 
Rock G, Ries JB and Udelhoven T (2011) Sensitivity Analysis of UAV-Photogrammetry for Creating Digital Elevation Models (DEM). : Proceedings of Conference on Unmanned Aerial Vehicle in Geomatics.

Rokhmana CA (2015) The Potential of UAV-based Remote Sensing for Supporting Precision Agriculture in Indonesia. Procedia Environmental Sciences 24: 245-253.

Ryan J, Hubbard A, Box J, Todd J, Christoffersen P, Carr J, et al. (2015) UAV photogrammetry and structure from motion to assess calving dynamics at Store Glacier, a large outlet draining the Greenland ice sheet. The Cryosphere 9(1): 1-11.

Shortis M, Robson S and Beyer H (1998) Principal point behaviour and calibration parameter models for Kodak DCS cameras. The Photogrammetric Record 16(92): 165-186.

Sieberth T, Wackrow R and Chandler JH (2014) Motion blur disturbs - the influence of motionblurred images in photogrammetry. The Photogrammetric Record 29(148): 434-453.

Sieberth T, Wackrow R and Chandler JH (2013) Automatic isolation of blurred images from UAV image sequences. International Archives of the Photogrammetry, Remote Sensing and Spatial Information Sciences XL-1/W2: 4-6.

Smith MW, Carrivick JL and Quincey DJ (2015) Structure from motion photogrammetry in physical geography. Progress in Physical Geography.

Smith MW and Vericat D (2015) From experimental plots to experimental landscapes: topography, erosion and deposition in sub-humid badlands from Structure-from-Motion photogrammetry. Earth Surface Processes and Landforms 40(12): 1656-1671.

Smith MJ, Chandler J and Rose J (2009) High spatial resolution data acquisition for the geosciences: kite aerial photography. Earth Surface Processes and Landforms 34(1): 155-161. 
Torralba A (2009) How many pixels make an image? Visual Neuroscience 26(01): 123-131.

Turner D, Lucieer A and de Jong SM (2015) Time series analysis of landslide dynamics using an unmanned aerial vehicle (UAV). Remote Sensing 7(2): 1736-1757.

Ught D (2001) An airborne direct digital imaging system. Photogrammetric Engineering \& Remote Sensing 67(11): 1299-1305.

van Blyenburgh P (1999) UAVs: an overview. Air \& Space Europe 1(5): 43-47.

Vasuki Y, Holden E, Kovesi P and Micklethwaite S (2014) Semi-automatic mapping of geological Structures using UAV-based photogrammetric data: An image analysis approach. Computers \& Geosciences 69: 22-32.

Verhoeven G, Karel W, Štuhec S, Doneus M, Trinks I and Pfeifer N (2015) Mind your grey tonesexamining the influence of decolourization methods on interest point extraction and matching for architectural image-based modelling. International Archives of the Photogrammetry, Remote Sensing and Spatial Information Sciences, XL XL-5/W4: 307-314.

Whitehead K, Moorman BJ and Hugenholtz CH (2013) Brief Communication: Low-cost, on-demand aerial photogrammetry for glaciological measurement. The Cryosphere 7(6): 1879-1884. 


\begin{tabular}{|c|c|c|c|c|c|c|c|c|c|c|}
\hline Application & Camera & $\begin{array}{l}\text { Camera } \\
\text { type }\end{array}$ & $\begin{array}{l}\text { Sensor } \\
\text { size } \\
(\mathrm{mm})\end{array}$ & Aperture & $\begin{array}{c}\text { Focal } \\
\text { length } \\
(\mathrm{mm}) \\
\end{array}$ & $\begin{array}{c}\text { Flight } \\
\text { height } \\
\text { (m) }\end{array}$ & $\begin{array}{c}\text { Shutter } \\
\text { speed } \\
\text { (s) }\end{array}$ & ISO & $\begin{array}{l}\text { Resolution } \\
\text { (MPs) }\end{array}$ & Reference \\
\hline $\begin{array}{l}\text { Moss survey } \\
\text { tundra }\end{array}$ & $\begin{array}{c}\text { Canon } \\
\text { Powershot } \\
\text { G10 }\end{array}$ & Compact & $\begin{array}{c}7.44 \times 5.5 \\
8\end{array}$ & Priority & 28 & 50 & $1 / 1000$ & $\begin{array}{c}200- \\
800\end{array}$ & 15 & $\begin{array}{c}\text { Lucieer et al., } \\
\text { (2011) }\end{array}$ \\
\hline $\begin{array}{l}\text { Landslide } \\
\text { monitoring }\end{array}$ & $\begin{array}{c}\text { Praktica } \\
\text { Luxmedia } \\
8213\end{array}$ & Compact & $\begin{array}{c}5.76 \times 4.2 \\
9\end{array}$ & $?$ & ? & 200 & $1 / 800$ & ? & 8 & $\begin{array}{l}\text { Niethammer } \\
\text { et al., (2010) }\end{array}$ \\
\hline River mapping & Canon a480 & Compact & $\begin{array}{c}6.17 \times 4.5 \\
5 \\
\end{array}$ & ? & ? & $10-70$ & ? & ? & 10 & $\begin{array}{l}\text { Fonstad et } \\
\text { al., (2013) }\end{array}$ \\
\hline $\begin{array}{l}\text { Fault zone } \\
\text { topography }\end{array}$ & $\begin{array}{c}\text { Canon } \\
\text { Powershot } \\
\text { SX230 }\end{array}$ & Compact & $\begin{array}{c}6.17 \times 4.5 \\
5\end{array}$ & ? & 5 & $150-300$ & ? & ? & 12 & $\begin{array}{l}\text { Johnson et } \\
\text { al., (2014) }\end{array}$ \\
\hline Glacial mapping & $\begin{array}{c}\text { Canon IXUS } \\
125 \mathrm{HS}\end{array}$ & Compact & $\begin{array}{c}6.17 \times 4.5 \\
5\end{array}$ & auto & 4.3 & 120 & $\begin{array}{l}1 / 320- \\
1 / 1200\end{array}$ & $\begin{array}{l}100- \\
250\end{array}$ & 16 & $\begin{array}{l}\text { Immerzeel et } \\
\text { al., (2014) }\end{array}$ \\
\hline Glacial mapping & $\begin{array}{c}\text { Panasonic } \\
\text { Lumix DMC- } \\
\text { LX5 }\end{array}$ & Compact & $\begin{array}{c}8.07 \times 5.5 \\
6\end{array}$ & f8 & 5.1 & 500 & $1 / 1600$ & ? & 10.1 & $\begin{array}{l}\text { Ryan et al., } \\
\text { (2015) }\end{array}$ \\
\hline $\begin{array}{l}\text { Habitat } \\
\text { monitoring }\end{array}$ & Canon S100 & Compact & $\begin{array}{c}7.60 \times 5.7 \\
0\end{array}$ & $\mathrm{f} 3.5$ & ? & 25 & $1 / 800$ & 400 & 12.1 & $\begin{array}{l}\text { Puttock et } \\
\text { al., (2015) }\end{array}$ \\
\hline $\begin{array}{l}\text { Biogeomorphic } \\
\text { mapping }\end{array}$ & $\begin{array}{c}\text { Olympus PEN } \\
\text { Mini E-PM1 }\end{array}$ & Compact & $\begin{array}{c}17.33 \times 1 \\
3.0\end{array}$ & ? & ? & 200 & ? & ? & 12.3 & $\begin{array}{l}\text { Hugenholtz } \\
\text { et al., (2013) }\end{array}$ \\
\hline $\begin{array}{l}\text { Landform active } \\
\text { volcano }\end{array}$ & Canon 5Dii & DLSR & $36 \times 24$ & auto/f8 & 35 & $700-1400$ & $\begin{array}{c}\text { auto/1/ } \\
800\end{array}$ & ? & 21 & $\begin{array}{l}\text { Nakano et } \\
\text { al., (2014) }\end{array}$ \\
\hline
\end{tabular}




\begin{tabular}{|c|c|c|c|c|c|c|c|c|c|c|}
\hline $\begin{array}{l}\text { Disaster } \\
\text { management }\end{array}$ & Canon 5Dii & DSLR & $36 \times 24$ & $?$ & $?$ & 3000 & $1 / 250$ & ? & 21 & $\begin{array}{l}\text { Chou et al., } \\
(2010)\end{array}$ \\
\hline Quarry & Canon 300D & DSLR & $\begin{array}{c}22.7 \times 15 \\
1\end{array}$ & Varies & 28 & $50-550$ & $?$ & ? & 6.3 & $\begin{array}{l}\text { Rock et al., } \\
\text { (2011) }\end{array}$ \\
\hline $\begin{array}{l}\text { Multi-temporal } \\
\text { landslide } \\
\text { monitoring }\end{array}$ & Canon 550D & DSLR & $\begin{array}{c}25.1 \times 16 \\
7\end{array}$ & f3.5 & 18 & 40 & $1 / 1200$ & 200 & 18 & $\begin{array}{l}\text { Lucieer et al., } \\
\text { (2014b) }\end{array}$ \\
\hline $\begin{array}{l}\text { Habitat } \\
\text { monitoring }\end{array}$ & Canon 550D & DSLR & $\begin{array}{c}25.1 \times 16 \\
7\end{array}$ & ? & ? & 50 & $?$ & ? & 18 & $\begin{array}{c}\text { Lucieer et al., } \\
\text { (2014a) }\end{array}$ \\
\hline $\begin{array}{l}\text { Structural } \\
\text { geology/faults/ } \\
\text { paleoseismology }\end{array}$ & Canon 550D & DSLR & $\begin{array}{c}25.1 \times 16 \\
7\end{array}$ & Varies & $18-55$ & $30-40$ & $?$ & ? & 15 & $\begin{array}{l}\text { Bemis et al., } \\
\text { (2014) }\end{array}$ \\
\hline $\begin{array}{l}\text { Moraine mound } \\
\text { topography }\end{array}$ & Canon EOS-M & DSLR & $\begin{array}{c}22.7 \times 15 \\
1\end{array}$ & ? & 22 & 100 & $1 / 1000$ & ? & 18 & $\begin{array}{c}\text { Tonkin et al., } \\
(2014)\end{array}$ \\
\hline $\begin{array}{l}\text { Soil erosion } \\
\text { measurement }\end{array}$ & $\begin{array}{l}\text { Panasonic } \\
\text { Lumix GF1 }\end{array}$ & $\begin{array}{l}\text { Interchange } \\
\text {-able lens }\end{array}$ & $18 \times 13.5$ & ? & 14 & ? & $?$ & ? & 12 & $\begin{array}{c}\text { d'Oleire- } \\
\text { Oltmanns et } \\
\text { al., (2012) }\end{array}$ \\
\hline $\begin{array}{l}\text { Soil erosion } \\
\text { measurement }\end{array}$ & Sony NEX 5 N & $\begin{array}{c}\text { Interchange } \\
\text {-able lens }\end{array}$ & $\begin{array}{c}23.5 \times 15 \\
6\end{array}$ & f6.3-f8 & 16 & $8-11$ & $?$ & $?$ & 16.1 & $\begin{array}{l}\text { Eltner et al., } \\
\quad(2013)\end{array}$ \\
\hline
\end{tabular}

Appendix 1. A sample of studies, showing camera settings and main objectives of each survey. ? Denotes unreported values. 